\title{
Heavy metals in selected vegetables from markets of Faisalabad, Pakistan
}

\begin{abstract}
Two hundred ten samples of selected vegetables (okra, pumpkin, tomato, potato, eggplant, spinach, and cabbage) from Faisalabad, Pakistan, were analyzed for the analysis of heavy metals: cadmium $(\mathrm{Cd})$, lead $(\mathrm{Pb})$, arsenic $(\mathrm{As})$, and mercury $(\mathrm{Hg})$. Inductively coupled plasma optical emission spectrometry was used for the analysis of heavy metals. The mean levels of $\mathrm{Cd}, \mathrm{Pb}, \mathrm{As}$, and $\mathrm{Hg}$ were $0.24,2.23,0.58$, and $7.98 \mathrm{mg} / \mathrm{kg}$, respectively. The samples with $\mathrm{Cd}(27 \%), \mathrm{Pb}(50 \%)$, and $\mathrm{Hg}$ (63\%) exceeded the maximum residual levels set by the European Commission. The mean levels of heavy metals found in the current study are high and may pose significant health concerns for consumers. Furthermore, considerable attention should be paid to implement comprehensive monitoring and regulations.
\end{abstract}

Keyword: Heavy metals; Inductively coupled plasma optical emission spectrometry; Vegetables 